\title{
O CONHECIMENTO POLÍTICO NA ATUAÇÃO DO ENFERMEIRO
}

\author{
The political knowing in the acting of the nurse
}

\section{El conocimiento político en la actuación del enfermero}

\author{
Karin Rosa Persegona ${ }^{1}$ \\ Maria Helena Lenardt ${ }^{3}$
}

\author{
Daniele Laís Brandalize Rocha² \\ Ivete Palmira Sanson Zagonel ${ }^{4}$
}

\section{RESUMO}

0 artigo tem por objetivo refletir acerca do conhecimento empírico, ético, estético e pessoal proposto por Carper e de um quinto padrão de conhecimento denominado sociopolítico segundo White. A Enfermagem, ao delimitar seu campo de atuação, necessita explicitar suas formas de conhecer, produzir e validar o conhecimento, para consolidar-se como disciplina e profissão que se organiza e expressa socialmente com identidade singular em um complexo campo de conhecimento. 0 padrão de conhecimento sociopolítico contribui para que o enfermeiro tenha uma visão abrangente, na qual se particulariza a responsabilidade e 0 compromisso como agente de mudança organizacional, social e política, investindo na inovação e sustentabilidade do processo de trabalho da enfermagem em defesa da saúde individual e coletiva.

Palavras-chave: Conhecimento. Cuidados de Enfermagem. Papel do Profissional de Enfermagem.

\begin{abstract}
This article objectifies to reflect on empirical, ethical, esthetical and personal patterns of knowing proposed by Carper as well as a fifth one called sociopolitical pattern of knowing according to White. By delimiting its acting field, nursing needs to explicit its ways of knowing, producing and validating knowledge in order to consolidate as a discipline and profession which is organized and socially expressed with unique identity in a complex knowledge field. The sociopolitical pattern of knowing contributes for nurses to have a broad view, particularly the responsibility and commitment as agents of organizational, social and political change, investing on the innovation and sustainability of nursing work process in favor of individual and collective health.
\end{abstract}

Key words: Knowledge. Nursing care. Nurse's role.

\section{Resumen}

El artículo tiene el objetivo de hacer una reflexión respecto al conocimiento empírico, ético, estético y personal propuesto por Carper y de un quinto patrón de conocimiento denominado socio político según White. La enfermería, al delimitar su campo de actuación necesita mostrar sus formas de conocer, producir y validar el conocimiento, para consolidarse como disciplina y profesión que se organiza y expresa socialmente con identidad particular en un complejo campo de conocimiento. El patrón de conocimiento socio político contribuye para que el enfermero tenga una visión global, en la cual se destaca la responsabilidad y el compromiso como agente de cambio orgánico, social y político invirtiendo en la innovación y mantenimiento del proceso de trabajo de enfermería en defensa de la salud individual y colectiva.

Palabras clave: Conocimiento. Atención de enfermería. Rol de la enfermera.

\footnotetext{
'Enfermeira. Mestre em Enfermagem pelo Programa de Pós-Graduação em Enfermagem da UFPR. Docente do Curso de Enfermagem das Faculdades Pequeno Príncipe (FPP), Curitiba/PR. Brasil. E-mail: karinrosap@yahoo.com.br, ²Enfermeira. Mestre em Enfermagem pelo Programa de Pós-Graduação em Enfermagem da UFPR. Docente do Curso de Enfermagem das Faculdades Pequeno Príncipe (FPP), Curitiba/PR. Brasil. E-mail: enferdani2004@yahoo.com.br, ${ }^{3}$ Enfermeira. Doutora. Professora Sênior do Programa de Pós-graduação em Enfermagem da UFPR. Coordenadora do GMPI (Grupo Multiprofissional de Pesquisa sobre Idosos/ UFPR), Curitiba/PR. Brasil. E-mail: lenardthart@hotmail.com, Enfermeira. Doutora. Docente do Programa de Pós-Graduação em Biotecnologia aplicada à Saúde da Criança e Adolescente das Faculdades Pequeno Príncipe (FPP). Coordenadora do Curso de Enfermagem das FPP. Coordenadora do Núcleo de Estudos, Pesquisa e Extensão em Enfermagem (NEPEE), Curitiba/PR. Brasil. E-mail: ivetesanzag@yahoo.com.br
} 
O conhecimento político na atuação do enfermeiro Persegona KR, Rocha DLB, Lenardt MH, Zagonel IPS

\section{INTRODUCÃO}

Na área de saúde, todos os profissionais realizam o cuidado, e o que difere no agir profissional de cada um é o modo como expressam esse cuidado. Essa reflexão conduz a pensar a Enfermagem enquanto disciplina da vida, envolta pelas transformações que a civilização está passando. Essas transformações incluem a crescente necessidade de valorização das pessoas, de seus valores e das formas como enfrentam o desenvolvimento e avanços tecnológicos e seus resultados sobre a vida humana. A enfermagem está fundamentada pelo cuidar, essência da profissão, com influência na vida das pessoas, pois representa, também, o meio de expressão e valorização do ser humano.

Nesse campo de atuação, em que as ações se concretizam no cuidar, percebe-se a necessidade de romper, no sentido de extrapolar o modelo biomédico e reconhecer a exigência da inclusão da representação da integralidade no cuidado. A concepção da realidade, alicerçada apenas nos padrões da racionalidade médica, não dá conta das múltiplas questões que envolvem o ser humano doente. Para se obterem respostas adequadas a estas interrogações, é preciso modificar o modo de conceber o cuidado de enfermagem. Esse movimento é importante e esperado, pois o avanço deve impulsionar os novos saberes, e estes, consequentemente, conduzir a novos fazeres em um ciclo interminável.

Os primeiros modelos conceituais de enfermagem seguiram uma forma empírica de construção de teorias, e, apesar disso, as diferentes propostas teóricas desenvolvidas buscaram novas formas de ver e pensar os fenômenos envolvidos na prática. Os enfermeiros acompanham o movimento que tem questionado a ciência e seus métodos, refletindo e discutindo outras formas de desenvolver o seu conhecimento específico'.

É possível questionar o que já foi construído, aprimorar formas de construir e implementar as novas construções para que o exercício profissional seja oxigenado, diversificado e constantemente refletido. Porquanto,

meditar sobre a ciência e sobre seu movimento próprio também é compreender seus erros do passado. Énesse sentido que a verdade só adquire seu pleno sentido no término de uma polêmica contra os erros passados. Eé por isso que não há verdade primeira, apenas erros primeiros ${ }^{2: 72}$.

A enfermagem, pelas características do objeto e finalidade do trabalho, utiliza diferentes instrumentos para viabilizar o cuidado atendendo às necessidades da população; entretanto, carece de reconhecimento em seu modo de ser, fazer e saber, 0 que exige uma reflexão e inserção também no contexto sociopolítico. A partir dos padrões de conhecimento empírico, ético, estético e pessoal, ${ }^{3}$ e do sociopolítico, ${ }^{4}$ insere-se a preocupação com a profissão, com a prática de enfermagem no contexto social e político da saúde.

0 padrão sociopolítico, denominado quinto padrão, é entendido como um desafio para a enfermagem porque "frequentemente aceitamos o reconhecimento pela atuação nos momentos de dor, nas crises e nos momentos de intimidade, situações nas quais o paciente encontra-se perturbado" "5:84. Porém, o enfermeiro necessita de reconhecimento pelas importantes contribuições à construção, decisão e execução de diretrizes políticas à saúde no país. A posição que muitos enfermeiros ocupam em cargos e encargos no setor saúde de forma cada vez mais crescente, na assistência e no delineamento das políticas de saúde exige a inserção do enfermeiro nos espaços decisórios. Ele é o profissional que possui preparo para o cuidado, bem como o conhecimento para a gestão desse cuidado; está apto para atuar nas diferentes formas de concretizar e pensar as ações de saúde.

Apesar dos avanços, ainda se constata no processo de trabalho do enfermeiro a imposição de outros profissionais, e, como consequência disto, verifica-se a subalternidade, que implica a visibilidade e prejuízos pessoais e profissionais para todos. É imperioso que se abram caminhos nesse modo de ser e fazer da categoria, com a inserção do enfermeiro nos espaços de gestão das políticas de saúde, a fim de ampliar conhecimentos e trazer inovações que repercutam cada vez mais nos profissionais e na sociedade.

0 enfermeiro articula em suas atividades o conhecimento teórico-conceitual às situações concretas vivenciadas, demonstra habilidades e competências para unir as funções assistencial, educacional e gerencial nas ações de cuidado, com facilidade e de forma conjunta, transita e tem competência para a atenção primária, secundária e terciária à saúde das pessoas. A ação gerencial do enfermeiro no cenário hospitalar relaciona-se, além de outras ações, à coordenação da equipe de enfermagem inter-relacionada às demais equipes para o alcance dos objetivos terapêuticos de recuperação e reabilitação do paciente. No cenário de saúde coletiva, o enfermeiro assume responsabilidades que vão além da condução da equipe de enfermagem. Assume a gerência de unidade de saúde, de programas de saúde, do processo de trabalho interdisciplinar, para alcance de objetivos coletivos ${ }^{6}$.

0 enfermeiro está inserido em todas as etapas do processo de trabalho em saúde, na administração, organização, coordenação, acompanhamento, tomada de decisão e avaliação das aç̃̃es desenvolvidas. Portanto, the incumbe conhecer, opinar, participar, decidir, intervir sobre as diretrizes sociais e políticas no delineamento das ações, pois a dimensão política é estabelecida pela capacidade de mobilizar grupos sociais de acordo com as demandas, necessidades e interesses da equipe e dos pacientes.

0 enfermeiro, ao desempenhar o papel gerencial em saúde, deve ter "a habilidade pessoal de interagir com grupos, indivíduos e de resolver problemas e conflitos, conduzir e reconduzir a missão e objetivos comuns para a ação cooperativa 
desejada"6:56, ou seja, envolve pessoas em detrimento de propostas, metas que pouco contribuem ou não se efetivam, por estarem descoladas das necessidades das pessoas.

0 padrão sociopolítico, ou quinto padrão, contribui para que 0 enfermeiro tenha uma visão abrangente com maior responsabilidade e compromisso, como agente de mudança organizacional, social e política. Esta visão investe na inovação do processo de trabalho, em defesa da saúde individual e coletiva, na busca de novas referências, de um modelo que atenda aos anseios das pessoas que necessitam de cuidado ${ }^{4} .0$ conhecimento ou padrão sociopolítico molda todos os demais padrões do saber, é considerado um conhecimento transversal aos demais, pois seu conceito contempla o contexto em que as pessoas interagem, em especial o enfermeiro e o paciente.

Cada um dos padrões de conhecimento é necessário para atingir o domínio da disciplina, mas nenhum, isoladamente, é considerado suficiente, pois "o conhecimento de enfermagem, para se constituir, conjuga componentes estéticos, éticos, empíricos e pessoais e, na prática profissional, é utilizado como um todo" $1: 39.0$ enfermeiro necessita instrumentalizar-se para realizar a prática profissional cotidiana, por meio do conhecimento da realidade, interligando diferentes saberes e fazeres, tendo como foco o paciente, sujeito das ações de cuidado.

0 enfermeiro pode tornar-se um agente de mudança, de inovação em potencial, subsidiado pelo conhecimento político, pois dispõe de instrumentos como poder e força, os quais deve utilizar com vistas à coletividade; ou seja, deve possuir conhecimento sobre o curso de como as questões de saúde são determinadas, repensar os condicionantes e determinantes da realidade como se apresentam, interferir politicamente nestas questões, bem como mobilizar as pessoas com as quais interage, para também agir; pois "o homem despolitizado compreende mal o mundo em que vive e é facilmente manobrado por aqueles que detêm o poder" 7:152.

Nesse sentido, propõe-se refletir sobre os padrões de conhecimento da enfermagem ${ }^{3,4}$.

\section{PADRÕES DE CONHECIMENTO ENFERMAGEM}

A proposição das bases da Enfermagem moderna, por Nightingale, na segunda metade do século XIX, pode ser considerada uma teoria de enfermagem. Afirma-se isso, pois sua produção aponta propostas conceituais e proposições teóricas e metodológicas de implementação para a prática, as quais respeitam os recursos e demandas da época. No século XX, a partir da década de 50, nos Estados Unidos, algumas enfermeiras começaram a teorizar este saber originado da prática, tendo como objetivo criar programas de educação próprios da enfermagem.

A determinação da natureza do conhecimento da enfermagem tem a contribuição das teorias de enfermagem pelas declarações teóricas e as implicações para a prática, as quais foram e continuam sendo replicadas, reafirmadas, validadas ou ressignificadas pelas próprias autoras ou por enfermeiros que as utilizam em suas práticas cotidianas.

No fim da década de 70, nos Estados Unidos, a publicação de um artigo com resultados derivados de uma tese de doutorado apresentou quatro padrões de conhecimento de enfermagem ${ }^{3}$, cuja importância é constatada no dia-a-dia do desempenho profissional do enfermeiro.

0 processo de globalização exige um novo perfil para o profissional enfermeiro, ou seja:

que Ihes possibilite construir sua própria cultura, seu corpo de conhecimentos e habilidades, divulgar seus resultados e romper paradigmas teóricos, imprimindo à profissão um caráter humanista e social e não somente tecnicista ${ }^{8: 69}$.

Adequar-se a esse novo perfil é também um processo, 0 qual é favorecido quando o enfermeiro integra os padrões de conhecimento. Cada padrão é parte de um todo maior do conhecimento, no qual cada um é essencial, tem aspecto distinto, traz contribuição para o todo; cada um é igualmente vital ${ }^{9}$.

Estes padrões descritos significaram um passo importante para o desenvolvimento do conhecimento de enfermagem, pois representam formas de conhecimento a serem aplicados na enfermagem.

0 padrão empírico é descrito como a ciência da enfermagem, sendo factual, descritivo, formulado discursivamente e verificável publicamente, tendo como objetivo desenvolver o conhecimento abstrato e explicações teóricas. Esta visão produz mudança de perspectiva na enfermagem, em razão da ênfase na competência técnica, no dever e na virtude e dá lugar à preocupação em determinar o que é efetivo na prática de enfermagem.

0 termo empírico define-se como aquele relativo apenas à experiência e, pois, sem caráter científico. No entanto, o padrão empírico na enfermagem é considerado um conhecimento que provém de perspectivas diversas, assim como da experiência científica.

0 padrão estético representa a arte da enfermagem, que é subjetiva, expressiva e concretiza-se no cuidar e não pode ser reduzida à simples execução de técnicas ou confundida com a arte doméstica, o que pode levar a uma desvalorização desta forma de conhecimento. Uma visão ampliada do que seja arte coloca em evidência as experiências de enfermagem, que se denominam estéticas, incluindo o processo criativo de descoberta no padrão empíico. A arte na enfermagem relacionase com a prática profissional, sendo expressa na interação enfermeiro-cliente, integrando habilidade técnica, integridade pessoal e coordenação corporal, utilizando o conhecimento, o julgamento e a habilidade na área clínica e tendo como componentes centrais a intuição, a interpretação, a compreensão e o valor'. 
O conhecimento político na atuação do enfermeiro Persegona KR, Rocha DLB, Lenardt MH, Zagonel IPS

0 padrão estético é a compreensão do significado em uma expressão subjetiva, única e particular que pode chamar-se de arte, ato, e possibilita mover-se além dos limites e circunstâncias de um momento particular, sentir o significado do momento e visualizar o que é possível. E torna-se visível por meio de ações, comportamentos, atitudes, condutas e interações do enfermeiro em resposta a outros 9 .

0 padrão ético não envolve apenas o conhecimento do código de ética profissional, mas sim o estabelecimento, pelos profissionais da enfermagem, de objetivos e intervenções que sejam adequados para que os clientes realizem escolhas, que avaliem o que é adequado e bom, certo e errado, valioso, desejável e correto. 0 desenvolvimento desse conhecimento se faz cada vez mais necessário, uma vez que os profissionais se veem cotidianamente confrontados com escolhas que apresentam caráter ético em meio a todo o desenvolvimento tecnológico existente e às condições concretas dos serviços de saúde!.

Fazer julgamentos éticos envolve, muitas vezes, confronto de valores, normas, interesses ou princípios e pode não resultar em respostas satisfatórias para um dilema ético ${ }^{9}$. Dessa forma, o conhecimento ético na enfermagem requer tanto um conhecimento implícito sobre o qual estão fundamentadas as decisões como o conhecimento dos princípios e teorias éticas sobre a enfermagem e a sociedade ${ }^{3}$.

0 padrão pessoal relaciona-se com 0 conhecimento, 0 encontro e o entendimento de si mesmo, que permite estabelecer um relacionamento de reciprocidade com o outro. Significa aproximar-se do cliente respeitando-o como sujeito, aceitando sua liberdade, promovendo a totalidade e a integridade no relacionamento pessoal, negando a manipulação e a impessoalidade. São identificados três aspectos do conhecimento pessoal: o conhecimento do próprio ser; 0 conhecimento explícito, teórico, articulado pela linguagem e aprendido na escola e refinado na prática, pelo conhecimento implícito ou prático; e o domínio de uma habilidade, expressando o saber fazer'1.

Os processos criativos de conhecimento pessoal são aberturas que permitem a absorção consciente da totalidade da experiência, alicerçados no centramento, que se entende como o processo de contemplação e introspecção constituído por um significado pessoal interior, experenciado na vida interior, pela personalidade, comportamentos, palavras e ações 9 .

0 quinto padrão de conhecimento ${ }^{4}$ é essencial para entender todos os outros. Entende-se como um conhecimento transversal, que perpassa aos demais. Os outros padrões se referiam a "quem", "como" e "o quê" na prática de enfermagem. 0 padrão de conhecimento sociopolítico refere-se à "em que meio". Isso nos leva a contemplar a enfermagem em um relacionamento introspectivo entre enfermeiro-paciente e a situação vivenciada em um amplo contexto no qual a enfermagem e saúde acontecem. Isso leva a enfermagem à questão de admitir como verdadeiras as hipóteses sobre sua prática, a profissão e as políticas de saúde 4 .

\section{o conhecimento político e a politicidade do cuidado de enfermagem}

0 conceito de política ou conhecimento político teve suas primeiras bases nos Tempos Homéricos (séculos XII a VIII a.C.), caracterizado pelos estudiosos como Política Antiga e Medieval. Neste período, o poder se concentrava nas mãos da aristocracia guerreira, predominando a crença nos mitos. As ações humanas se explicavam pela interferência dos deuses, e as leis que regiam o comportamento humano também tinham origem divina?.

No Período Arcaico (séculos VIII a VI a.C.), aconteceu o desenvolvimento do comércio, e consequentemente da polis, cidade-estado grega, palavra da qual se originou o termo política, que é descrita como "atividade que diz respeito à vida pública, arte de governar, de gerir os destinos da cidade". Logo, político é definido como "cidadão que atua na vida pública e é investido de poder para imprimir determinado rumo à sociedade, tendo em vista o bem comum"7:151.

Este período se caracterizou por grandes avanços no campo da política, proporcionados pelo desenvolvimento das primeiras leis escritas, uso da moeda e surgimento da filosofia e dos conceitos de cidadania, sendo considerados cidadãos somente $10 \%$ da população, excluindo estrangeiros, mulheres e escravos. Surge também o conceito de democracia, que tinha como um dos principais ideais o de que "o cidadão pode e deve atuar na vida pública independente da origem familiar, classe ou função. Todos são iguais, com o mesmo direito à palavra e à participação no exercício do poder" ${ }^{\prime 7: 157 .}$

Ao longo da história humana, o conhecimento político foi e continua sendo desenvolvido e aprimorado, por tratar-se de um conhecimento e uma prática que interfere na vida de todos os cidadãos, principalmente nos setores de saúde, educação e legislação, devendo, portanto, ser entendido e praticado por todos.

0 conhecimento político primordialmente possui duas bases para suas relações e efetivação: força e poder.

0 poder diz respeito à:

capacidade ou possibilidade de agir, de produzir efeitos (sobre indivíduos ou grupos humanos). Portanto, o poder não é um ser, mas uma relação. Mais ainda, é um conjunto de relações, por meio das quais indivíduos ou grupos interferem na atividade de outros individuos ou grupos ${ }^{7: 150}$.

Este poder só se concretiza por meio de forças, que são caracterizadas como criativas, que atuam e movimentam as relações humanas, forças física, psíquica e moral, forças estas positivas, energias que possibilitam viver melhor e enfrentar as dificuldades da vida.

Estas forças são intrínsecas ao ser humano, que o fazem viver e se relacionar com outros seres humanos, de maneira dinâmica, segundo interesses coletivos, portanto, vital. Nossas relações sociais com outros seres humanos nos fazem ser o que somos, com nossas ideias e desejos em comum, e é nessa 
"comunidade", com a união de forças positivas, que a vida em sociedade acontece; o que não poderia ser diferente quando pensamos a relação enfermeiro e paciente.

A política, no uso generalizado da palavra, é toda modalidade de direção de grupos sociais que envolva poder, administração e organização, tanto no plano público quanto no privado. A política atua de modo que, a cada solução encontrada, novo conflito ou nova luta podem surgir, exigindo novas soluções. Ao invés de reprimir os conflitos pelo uso da força e da violência das armas, a política aparece como trabalho legítimo dos conflitos, de forma que um fracasso nesse trabalho seria a causa do uso da força e da violência ${ }^{10}$.

Conhecimento sociopolítico ${ }^{4}$ pode ser conceituado e compreendido sob dois aspectos. 0 primeiro aspecto refere-se ao contexto sociopolítico das pessoas envolvidas no ato de cuidar de enfermagem, ou seja, o enfermeiro e o paciente, contexto em que há interação entre ambos. 0 segundo aspecto refere-se à prática profissional do enfermeiro, ou seja, inclui 0 conhecimento que a sociedade tem sobre o papel do enfermeiro, bem como o conhecimento que o enfermeiro tem sobre a sociedade e suas políticas, sociais e econômicas, em que atua.

Nesta perspectiva, o conhecimento sociopolítico visa demonstrar ao enfermeiro a abrangência que poderá ter sua prática profissional na sociedade, que suas ações podem ir além do espaço no qual atua diretamente, seja ele hospitalar, domiciliar, entre outros, podendo realizar mudanças nesta sociedade, nas questões políticas e sociais da saúde humana.

0 contexto sociopolítico da interação enfermeiro-paciente está relacionado fundamentalmente à identidade cultural de ambos, posto que a cultura influencia o entendimento de cada pessoa sobre sua saúde e doença, sua linguagem, identidade e conexão com sua origem ${ }^{4}$. Ou seja, "em que meio", em qual contexto estas pessoas vivem? Que conhecimento possuem sobre sua condição?

Cabe ao enfermeiro ter a sensibilidade e o conhecimento para respeitar e cuidar, de forma singular, no complexo campo de conhecimentos, de intervenção e de responsabilidade social próprios, que constituem sua identidade profissional em relação à comunidade e às outras profissões.

0 padrão sociopolítico tem implicações culturais, ou seja, é culturalmente determinado, pois "o homem é o resultado do meio cultural em que foi socializado. Ele é um herdeiro de um longo processo acumulativo, que reflete o conhecimento e a experiência adquirida pelas numerosas gerações que 0 antecederam"1:45. Isto reforça nosso entendimento sobre a cultura como um aspecto ligado e particularizado de cada grupo humano.

A natureza inerentemente política da enfermagem se expressa em seu marco ético, conceitual e prático, enquanto pensa nas populações, se ocupa dos determinantes sociais da saúde e produz intervenções sociais orientadas à equidade; ela representa um ato de distribuição de poder, que permite, mediante uma ação social deliberada, construir um mundo mais justo ${ }^{12}$.
Entendendo-se que as ações do enfermeiro podem ter finalidades individuais e coletivas, e que estas devem respeitar o pertencimento cultural de cada indivíduo, é pertinente refletir sobre os instrumentos que este profissional utiliza em seu processo de trabalho, sobretudo os conhecimentos que moldam seu agir.

No processo de trabalho, o enfermeiro busca levantar os problemas ou situações as quais requerem conhecimentos $\mathrm{e}$ intervenções. Instrumentalizado pelo conhecimento político, o enfermeiro utiliza o poder e a força para mobilizar o paciente ou seus responsáveis a tornarem-se corresponsáveis pelos cuidados. Este processo reflete uma das características da politicidade do cuidado.

Ao refletirmos sobre o conhecimento político, enquanto subsídio para o agir do enfermeiro, pode-se caracterizá-lo como objeto epistemológico transversal, aquele que se entrelaça a todos os padrões de conhecimentos necessários para oferecer a oportunidade de exercer o papel próprio e atuante no processo de cuidar. A politicidade do cuidado é a "habilidade humana de saber pensar e intervir criticamente, em uma busca imanente por autonomia crescente" 13:730, tanto a nível individual como coletivo dos sujeitos de seu processo de trabalho, no sentido de prover subsídios para que os sujeitos do seu processo de trabalho possam optar e opinar sobre questões que interferem diretamente sobre sua saúde, necessitando de tomada de decisões.

Nesta perspectiva, a politicidade do cuidado pode:

auxiliar no fortalecimento de processos de saúdedoença mais autônomos, centrados nos sujeitos (...) e no entendimento ampliado do ato políticoque tendencialmente cuida, domina e tutela, mas que, também, pode libertar pelo mesmo ato subjetivamente produzido ${ }^{13: 736}$.

O conhecimento político e a "politicidade" do cuidado no contexto de atuação do enfermeiro são direcionadores à prática profissional, pois articulam atitudes, direitos, relações, com ênfase na ética e humanismo para auxiliar as pessoas que atuam na enfermagem e aqueles que necessitam de cuidados a alcançarem a autonomia e emancipação. Entender esse entrelaçamento de responsabilidade entre os envolvidos leva a repensar a prática, refletir sobre as demandas e resultados, compartilhar com o outro.

\section{CONSIDERAÇÕES FINAIS}

A Enfermagem é uma disciplina voltada à vida dos indivíduos que vivem em diversos locais e procedem de diferentes pertencimentos culturais. Isto significa, frequentemente, divergentes visões e concepções de saúde e doença. Neste contexto, o conhecimento político torna-se fundamental para subsidiar 0 agir da enfermagem na sociedade, ao admitirmos 
que a política é uma dimensão que faz parte da vida do ser humano e permeia todas as atividades humanas o tempo todo.

0 padrão de conhecimento sociopolítico aplicado isoladamente não tem sentido; entretanto, ao ser associado aos demais conhecimentos, acrescenta direção e sustentabilidade ao cuidado à saúde, no nível pessoal dos indivíduos e dos profissionais de enfermagem.

Somente com referenciais apropriados à prática profissional do enfermeiro é que as demandas de cuidado se estabelecem de forma integral, fortalecendo quem oferece o cuidado e aqueles que o recebem. Com o desenvolvimento do conhecimento, são reafirmadas as questões epistemológicas da ciência de enfermagem, pois, pela pesquisa e aprimoramento da prática, é possível expor a extensão do conhecimento e os critérios de seu alcance.

0 conhecimento empírico tende a ser o mais utilizado e enfatizado pela enfermagem, pelas próprias características e necessidades de organizar as ações de cuidar de acordo com os fenômenos de interesse dos enfermeiros. Porém, a utilização isolada parcela o saber, o fazer e o pensar que a ciência de enfermagem exige.

Nesse sentido, aliar as distintas formas de conhecimento possibilita saber como o conhecimento é organizado com o uso de teorias e leis, como ocorre com o uso da sensibilidade, experiência, integralidade, código moral da enfermagem, associado ao padrão sociopolítico. Nenhum padrão pode ser utilizado de forma isolada, pois são inter-relacionados e interdependentes. Os enfermeiros, ao utilizarem os distintos padrões de conhecimento de enfermagem, atribuem valor à

\section{REFERÊNCIAS}

1 Cestari ME. Padrões de conhecimento da enfermagem e suas implicações no ensino. Rev Gaucha Enferm 2003 abr; 24(1): 34-42. 2 Japiassu H. Introdução ao pensamento epistemológico. $7^{\mathrm{a}}$ ed. Rio de Janeiro (RJ): Francisco Alves; 1992.

3 Carper BA. Fundamental patterns of knowing in nursing. Adv Nur Sci 1978 1(1):13-23.

4 White J. Patterns of knowing: rewiew, critique, and update. Adv Nurs Sci 1995; 17(4): 73-86.

5 Dal Pai D, Schrank G, Pedro ENR. 0 enfermeiro como ser sóciopolítico: refletindo a visibilidade da profissão do cuidado. Acta Paul Enferm 2006; 19(1): 82-7.

6 Peterlini OLG. Cuidado gerencial e gerência do cuidado na interface da utilização do sistema de informação em saúde pelo enfermeiro [dissertação de mestrado]. Curitiba (PR): Programa de Pós-Graduação em Enfermagem/UFPR; 2004.

7 Aranha MLA, Martins MHP. Temas de filosofia. $2^{a}$ ed. São Paulo(SP): Moderna; 2000. prática, a partir de uma perspectiva ampliada na solução de problemas durante a efetivação do cuidado significativo.

0 profissional de enfermagem necessita articular os diferentes padrões do conhecimento para atingir a verdadeira integração entre pesquisa, prática e teoria, por meio de distintas metodologias, competências e fontes do conhecimento válidos e apropriados para seus propósitos. Os padrões do conhecimento, empírico, estético, pessoal, ético e sociopolítico podem ser utilizados em diferentes contextos de atuação profissional e em distintas fases do ciclo vital, sempre tendo como imperativo o cliente, sujeito das ações de cuidar. Cada padrão é essencial e depende dos demais para formar o todo da prática profissional.

Este artigo induz o enfermeiro à reflexão da prática, teoria e pesquisa, pois indica a utilização simultânea das distintas formas de ver o outro e auxiliar na superação da dor e sofrimento causados pelo adoecimento. 0 conhecimento estético do cuidar enfatiza a sensibilidade, o significado do momento; o pessoal é subjetivo, promove a integralidade; 0 ético ocorre à medida que surgem dilemas morais, o empírico é objetivo e passível de quantificação; e o sociopolítico produz intervenções sociais orientadas à equidade.

Aos enfermeiros cabe utilizar e ensinar a utilizar os padrões do conhecimento na prática profissional, sendo importante reconhecer que a valorização de um padrão como exclusivo ou superior restringe a capacidade de evolução da ciência de enfermagem. Essa aprendizagem seria também a garantia do exercício da cidadania ativa, que permite a melhor atuação profissional nas decisões e abre oportunidades para a gestão sustentável do cuidado à saúde.

8 Palmeira IP, Rodriguéz MB. A investigação científica no curso de enfermagem: uma análise crítica. Anna Nery Rev Enferm 2008 mar; 12(1): 68-75.

9 Chinn PL, Kramer MK. Nursing theory as an expression of empirics. In: Chinn PL, Kramer MK. Theory and nursing: a systematic approach. St. Louis (USA): Mosby; 1995.

10 Chauí M. Convite à filosofia. 13ª ed. São Paulo(SP): Ática; 2005.

11 Laraia RB. Cultura: um conceito antropológico. 19a ed. Rio de Janeiro(RJ): J Zahar; 1992.

12 Malvárez S. El reto de cuidar en un mundo globalizado. Texto Contexto Enferm 2007 jul/set; 16(3): 520-30.

13 Pires MRGM. Politicidade do cuidado como referência emancipatória para a enfermagem: conhecer para cuidar melhor, cuidar para confrontar, cuidar para emancipar. Rev Latino-am Enfermagem 2005 set/out; 13(5): 729-36. 